\title{
ENTRE EL SABER Y LA IGNORANCIA
}

\author{
Josep M. Vilajosana \\ Universitat Pompeu Fabra, Barcelona
}

RESUMEN. El falibilismo supone un desafío a la concepción tradicional del saber, pero es la razón que subyace a la valoración positiva de ciertos tipos de ignorancia. Una respuesta al desafío sería negar que la verdad de «p» sea una condición necesaria para saber que $p$, lo que lleva al relativismo. En este caso, se cambia el concepto de saber. Una segunda opción supone mantener dicha condición, lo cual conduce al agnosticismo. En este caso, la ignorancia ya no es lo contradictorio del saber, sino que está en otro nivel. Si se sostiene la tesis relativista, se puede justificar el reproche que suele hacerse a algún tipo de ignorancia, pero al precio de sostener un concepto de saber contraintuitivo. La tesis agnóstica, en cambio, no tiene las consecuencias contraintuitivas del concepto de saber relativista, pero no permite censurar a nadie por su ignorancia.

Palabras clave: Ernesto Garzón Valdés, conocimiento, ignorancia, falibilismo.

ABSTRACT. The falibilism supposes a challenge to the traditional conception of knowledge, but it is the reason for which certain types of ignorance are appraised positively. An answer to this challenge is to deny that the truth of " $p$ " is a necessary condition to know that $p$. This is a relativist answer. In this case, the concept of knowledge will change. A second option implies sustaining this condition, which drives to agnosticism. In this case, ignorance is not any more the contrary of knowledge, but is at another level. When one holds the relativistic thesis, one will be able to justify the reproach that is usually made to some type of ignorance, but at the price of holding a contra-intuitive concept of knowledge. The agnostic thesis, however, does not have the negative consequences of the relativist concept of knowledge, but it does not allow to criticize anybody because of their ignorance.

Keywords: Ernesto Garzón Valdés, knowledge, ignorance, falibilism. 
n un sugerente y elegante trabajo (GARZÓn, 1999), GARZÓN VALDÉS distingue 8 clases de ignorancia: excusante, presuntuosa, culpable, racional, docta, conjetural, inevitable y querida. De ellas, las tres primeras las califica de formas negativas, que hay que evitar, mientras que las restantes deben ser aceptadas o bien porque son insuperables o bien porque nos ayudan a asumir nuestra condición humana y pueden tener una benéfica influencia en nuestras vidas.

GARZÓN también realiza una afirmación que, en principio, parece difícil negar: la ignorancia es el opuesto contradictorio del saber. En efecto, uno ignora algo en la medida en que no lo sabe ${ }^{1}$. Si esto es así, el concepto de ignorancia depende del concepto de saber. Puede resultar interesante, entonces, realizar un somero análisis del concepto de saber y ver qué efectos tiene en la concepción de la ignorancia defendida por GARZÓN.

Según el concepto tradicional de saber, se entiende que para poder afirmar que alguien sabe algo se requieren tres condiciones. Teeteto, en el diálogo que lleva su nombre, le responde a SÓCRATES que el saber es «opinión verdadera» (Teeteto, 200e) y recuerda más adelante: «le oí decir a una persona [...] que la opinión verdadera acompañada de una explicación es saber» (Teeteto, 201cd).

Puede decirse, entonces, que $S$ sabe que $p$ si y sólo si:

1. $S$ cree que $p$,

2. «p» es verdadera,

3. S tiene razones suficientes para creer que $p$.

Este esquema suele ajustarse bastante bien a nuestro uso ordinario de la palabra «saber», aunque no ha estado exento de críticas. Muchas de ellas se han dirigido a sugerir que se requería una cuarta condición adicional para dar cuenta de ciertos posibles contraejemplos. Pero este no es el punto que aquí me interesa destacar. Centraré mi atención, en cambio, en el papel que se le asigna a la verdad de «p» como exigencia del saber y qué repercusiones puede tener esta exigencia respecto al concepto de ignorancia.

Hay que destacar que el factor principal que sirve para que GARZÓN valore positivamente algunos tipos de ignorancia es la constatación de la falibilidad del saber. Así, la docta ignorancia, entendida como disposición a reconocer las limitaciones de todo saber racional desembocará en la ignorancia conjetural y en la necesidad de reconocer la existencia de una ignorancia inevitable. GARZÓN tiene presente la posición de Karl POPPER, según el cual: «sólo rara vez tenemos éxito al adivinar la verdad; y nunca podemos estar seguros de haberlo conseguido. Esto tenemos que hacerlo con conocimiento por conjetura» (POPPER, 1994: 60).

Si esto es así, podemos preguntarnos ¿cómo afecta el desafío falibilista a la segunda condición del saber? Creo que pueden darse al respecto dos respuestas, a las que voy a llamar, respectivamente, tesis relativista y tesis agnóstica.

${ }^{1}$ Aquí dejo de lado las complicaciones que conlleva el hecho de que el saber y, por tanto, la ignorancia pueden ser graduales. Asimismo, me ocuparé sólo del saber proposicional; el saber práctico plantea problemas específicos que quedan al margen de este trabajo. 
El punto de partida de la tesis relativista sería el reconocimiento de que la corrección de un saber basado en nuevas razones no implica necesariamente que no estuviéramos justificados en nuestro saber antes de tenerlas (véase, por ejemplo, VILLORO, 1982). ¿Sabían los físicos del siglo XVII que la luz tenía siempre una trayectoria rectilínea? Estaremos tentados a sostener que ahora nosotros sabemos que ellos se equivocaban, porque ahora tenemos razones que nos muestran que esa proposición no es verdadera. Ahora bien, según la tesis que comentamos, pese a admitir que sea falso lo que creían, si nos tomamos en serio el falibilismo, entonces ellos, para juzgar lo que sabían, tenían la misma garantía que tenemos nosotros para juzgar que sabemos otras proposiciones de la ciencia contemporánea, las cuales más tarde, a la luz de razones que ahora nos resultan inaccesibles, podrían mostrarse equivocadas. En este caso, afirmar $\ll S$ sabe que $p »$ sólo implicaría sostener que a partir de las razones disponibles, se puede inferir que no hay otras razones accesibles a la comunidad epistémica de $S$, susceptibles de revocar su saber, pero no implica que no pudieran haber otras razones, accesibles a otras comunidades epistémicas, capaces de revocarlo. Quien adhiera a esta posición estará sosteniendo otro concepto de saber, ya que eliminará la segunda condición y relativizará la tercera ${ }^{2}$, que quedará formulada de este modo:

3'. S tiene razones suficientes, dentro de las accesibles a la comunidad epistémica $C$, para creer que $p$.

Esta tesis puede tener algunas ventajas en el orden teórico, ya que es una vía interesante para enfrentar los clásicos desafíos planteados por GETTIER (GETTIER, 1963) y por HaRman (HARMAN, 1973). Pero este punto no puedo desarrollarlo aquí. También podría ser ventajosa esta tesis para el esquema presentado por GARZÓN, al menos en relación con los casos reprochables de ignorancia. Esto es así, por cuanto no resulta aceptable reprocharle a alguien una conducta basada en consideraciones falsas (como sería el caso de la ignorancia excusante y de la ignorancia culpable) si aceptamos que no hay acceso a la verdad. En cambio, sí que podemos exigirle a una persona que sea cuidadosa y atienda a las razones accesibles a su comunidad epistémica.

Pero el concepto relativista de saber tiene también claros inconvenientes. Por de pronto, se aparta considerablemente del uso ordinario de la palabra «saber». Resulta muy extraño afirmar que DESCARTES sabía en el siglo XVII que la luz tiene siempre una trayectoria rectilínea y que ahora sabemos que no es así. No digo que ambas afirmaciones sean contradictorias, porque no lo son a tenor de la definición dada. Sólo afirmo que se alejan tal vez de manera injustificada de nuestros usos lingüísticos. Además, llevaría a consecuencias claramente contra intuitivas. Por ejemplo, deberíamos sostener que GALILEO se equivocaba a la hora de sostener la teoría heliocéntrica, sencillamente porque las suyas no eran razones accesibles a la comunidad epistémica de su época.

Habría otra forma de acusar recibo del falibilismo, pero sin renunciar a la segunda condición. $\langle S$ sabe que $p »$ implicará la verdad de $\langle p »$, a diferencia de la tesis relativista y al igual que la concepción tradicional. Ahora bien, si aceptamos el falibilismo, nunca podemos estar seguros de la verdad de «p». Por lo tanto, nunca podemos estar seguros de que $S$ sabe que $p$. ¿Qué consecuencias deberíamos extraer de esta conclusión

${ }^{2}$ Debe quedar claro, para evitar confusiones, que de lo que se predica el carácter relativo en esta tesis es del saber y no de la verdad. 
respecto al concepto de ignorancia? Creo que la fundamental es la siguiente: no estar seguros de que $S$ sabe que $p$, no equivale a estar seguros de que $S$ no sabe que $p$.

Entre quien afirma que Dios existe (creyente) y quien lo niega (ateo), se encuentra el agnóstico que suspende el juicio, justamente por razones epistémicas. Uno de los dos, creyente o ateo, tiene razón, pero no podemos saber quién es, dirá el agnóstico. Para aplicar esta idea al problema que nos ocupa, quizás sea conveniente distinguir dos niveles. En el primer nivel, con independencia de que nosotros lo sepamos o no, «p» es verdadera o falsa. Si «p» es verdadera, entonces se cumple la segunda condición y, dando por descontadas las restantes, $S$ sabe que $p$. En cambio, si «p» es falsa, $S$ ignora que $p$, aunque se den las demás condiciones. En un segundo nivel, que es donde incide el falibilismo, no sabemos si $S$ sabe que $p$, pero tampoco sabemos si $S$ ignora que $p$. Llamar a esta incertidumbre «ignorancia» es cambiar el sentido que se ha estado utilizando hasta ahora. La ignorancia conjetural y la inevitable, que GARZÓN considera dignas de alabanza, pudieran no ser después de todo, supuestos en el que «ignorancia» sea el contradictorio de «saber».

Nótese, además, que este sentido de ignorancia, al que podemos llamar «agnóstico», pone en entredicho lo razonable de la llamada docta ignorancia, esa curiosa certidumbre epistémica del escéptico. Por eso, frente al dictum socrático «Sólo sé que no sé nada» hallamos la expresión doliente de SAN AGUSTín: «iAy de mí que ni siquiera sé lo que no sé!».

Por último, si se sostiene un concepto agnóstico de ignorancia, resulta indudable que existe una ignorancia invencible, la cual hay que asumir como muestra de nuestra condición humana. Pero, en cambio, parece difícil justificar el reproche al ignorante, por cuanto precisamente se asume que la ignorancia es inevitable, está fuera de nuestro control.

Podemos resumir lo dicho en 5 conclusiones:

1. El falibilismo supone un desafío a la concepción tradicional del saber y, en concreto, a la segunda condición, pero es la razón que subyace a la valoración positiva de ciertos tipos de ignorancia.

2. Una respuesta al desafío sería negar que la verdad de «p» sea una condición necesaria para saber que $p$, lo que lleva al relativismo. En este caso, se cambia el concepto de saber.

3. Una segunda opción supone mantener dicha condición, lo cual conduce al agnosticismo. En este caso, se introduce un nuevo concepto de ignorancia, que ya no es lo contradictorio del saber, sino que está en otro nivel.

4. El relativismo ayudaría a encontrar una cierta justificación al reproche que podemos hacer a algunos tipos de ignorancia, pero al coste de tener que sostener un concepto de saber muy alejado de nuestros usos lingüísticos y de consecuencias contra intuitivas.

5. El agnosticismo, por su parte, no tiene las consecuencias contra intuitivas del relativismo y da cuenta del carácter inevitable de la ignorancia. Ahora bien, al mantener esta posición, por un lado, debemos asumir un concepto de ignorancia de segundo nivel y, por otro lado, resulta muy difícil reprocharle a alguien su ignorancia, ya que ésta escapa a su control y en todo caso nunca podemos saber cuándo se da. 
Quisiera acabar recordando unas palabras de Einstein. Decía el eminente físico: «Todos somos muy ignorantes. Lo que ocurre es que no todos ignoramos las mismas cosas». Uno desearía poder llegar a ignorar las mismas cosas que Ernesto. Es difícil concebir un grado más excelso de sabiduría al que un ser humano falible pueda aspirar.

\section{BIBLIOGRAFÍA CITADA}

GARZÓN, E., 1999: «Algunas reflexiones sobre la ignorancia», Isonomía, 11: pp. 129-148.

GETTIER, E. L., 1963: «Is justifified belief knowledge?», Analysis, 23: pp. 121-123.

Harman, G., 1973: Thougt, Princeton: Princeton University Press.

Platón, 1998: Teeteto, Madrid: Gredos, pp. 137-317.

POPPER, K., 1994: «Sobre el conocimiento y la ignorancia», En busca de un mundo mejor, Barcelona: Paidós, pp. 51-66.

VILLORO, L., 1982: Creer, saber y conocer, México: Siglo XXI editores. 